\title{
EFFECTS OF A HYPERTHYROID COMPOUND ON APPETITE, BODY WEIGHT CHANGE AND OESTRUS INHIBITION IN GILTS FED A DITHIOCARBAMOYLHYDRAZINE (ICI 33828)*
}

\author{
F. W. STRATMAN \\ University of Wisconsin, Madison, U.S.A. \\ (Received 10th April 1969, revised 3rd Fune 1969)
}

\begin{abstract}
Summary. Sixty-three cycling gilts were assigned randomly to be started on treatment on Day 13 of the oestrous cycle. Treatments consisted of the following $-0,50$ and $150 \mathrm{mg}$ of a dithiocarbamoylhydrazine (ICI 33828) and 0, 1000 and $2000 \mathrm{mg}$ of iodinated casein (Protamone) in all combinations administered in $1.82 \mathrm{~kg}$ of feed per day for 10 days.

Iodinated casein significantly reduced gain in body weight while ICI 33828 had no significant effect. Only ICI 33828 significantly reduced feed consumption. Both iodinated casein and ICI 33828 at the higher doses significantly lengthened the interval from withdrawal to oestrus.

Iodinated casein, a hyperthyroid compound, failed to overcome the apparent hypothyroid effect of ICI 33828 on reproduction in the gilt under the conditions of this experiment.
\end{abstract}

\section{INTRODUCTION}

There is ample evidence that normal reproductive function is dependent on proper thyroid activity (Maqsood, 1952; Reineke \& Soliman, 1953). Either hypo- or hyperthyroidism results in modified reproductive physiology. Hyperthyroidism is known to cause irregular oestrous cycles, atrophic ovaries or incomplete folliculogenesis (Peterson, Webster, Rayner \& Young, 1952), increased sensitivity of the ovary to gonadotrophins (Leathem, 1958) and decreased LH and FSH potency of the pituitary (Chu, 1944) while hypothyroidism causes ovarian degeneration, arrested folliculogenesis, ovulation failure, irregular oestrous cycles, decreased sensitivity of the ovary to gonadotrophins and increased LH and FSH potency of the pituitary (Warner \& Meyer, 1949) depending on the species studied. These hypothyroid effects are similar to those shown by gilts when fed a dithiocarbamoylhydrazine, ICI 33828 (Stratman

\footnotetext{
* Department of Meat and Animal Science, Paper No. 507.
} 
\& First, 1969). ICI 33828 is known to inhibit thyroid function in the rat (Tulloch, Crooks \& Brown, 1963). Tulloch et al. (1963), on the basis of the reduced discharge of thyroid hormone labelled with ${ }^{131}$ iodine and the reduction of thyroid uptake of ${ }^{131}$ iodine in rats treated with ICI 33828, postulated that this compound had a direct effect on the thyroid gland and subsequently influenced thyroid stimulating hormone (TsH). Thus, the author postulated that the oestrus-inhibiting effect of the dithiocarbamoylhydrazine is due to a hyperthyroid condition. Iodinated casein (Protamone, 3.32\% thyroxine) administered in a sufficient dose, has the effect of a hyperthyroid gland and should reverse the postulated hypothyroid action of the dithiocarbamoylhydrazine, thereby reducing or eliminating its effects on the inhibition of oestrus and appetite.

An experiment was conducted to test the hypothesis that ICI 33828 inhibits oestrus by suppression of the thyroid gland.

\section{MATERIALS AND METHODS}

Sixty-three cycling crossbred (Duroc $\times$ Yorkshire) gilts were assigned randomly to the following $3^{2}$ factorial experiment. The treatments consisted of three levels of ICI 33828 (1 $\alpha$-methylallylthiocarbamoyl-2-methylthiocarbamoylhydrazine, Ayerst Laboratories, New York-0 mg, $50 \mathrm{mg}$ and $150 \mathrm{mg}$ ) and three levels of iodinated casein (Protamone, Agri-Tech Inc., Kansas City$0 \mathrm{mg}, 1000 \mathrm{mg}$ and $2000 \mathrm{mg}$ ) fed in all combinations in $1.82 \mathrm{~kg}$ of the basal diet (Stratman \& First, 1969).

Day 1 of the oestrous cycle (1st day of oestrus) was determined by checking the gilts for oestrus once daily with a boar. The gilts were individually fed once daily, their assigned rations beginning on Day 13 of the oestrous cycle. The gilts were returned to the basal diet, fed at the rate of $1.82 \mathrm{~kg}$ once daily, after 10 days of feeding the experimental rations. The gilts were weighed at the beginning and end of the 10-day experimental feeding period. Diet weighbacks were recorded at the end of the experimental period (10 days). Observations were made for any abnormal effects of the diet. Each gilt was checked once daily with a boar for oestrus during the experimental period and for 20 days thereafter. Intervals from the beginning of the feeding to oestrus were recorded. Gilts not returning to oestrus by 20 days after the experimental feeding period were slaughtered and their ovaries examined.

All data were tested statistically by analysis of variance and a multiple range test.

\section{RESULTS AND DISCUSSION}

There were no significant interactions among treatments $(P>0.05)$ in the mean body weight changes and mean feed consumption which are shown in Table 1. The initial body weights did not differ significantly either by main treatment effects or by treatment combinations $(P>0.05)$.

Gilts fed $1000 \mathrm{mg}$ and $2000 \mathrm{mg}$ of iodinated casein per day for 10 days lost significantly $(P<0.01)$ more weight $(-4.8 \mathrm{~kg}$ and $-5.6 \mathrm{~kg})$ than the gilts not 
receiving the drug $(+0.8 \mathrm{~kg})$. Iodinated casein is known to increase the basal metabolic rate and to reduce weight gains (Reineke \& Soliman, 1953). Lactating sows fed thyroprotein also exhibit an increased loss of body weight (Dudley, Becker, Jensen \& Terrill, 1956; Johnson, Hays, Speer \& Catron, 1959; Wahlstrom, 1959). Johnson et al. (1959) reported that the effect of thyroprotein on respiration rate, heart rate and rectal temperature is dose dependent.

Total feed consumption was not significantly $(P>0 \cdot 05)$ decreased by feeding

TABLE 1

BODYWEIGHT CHANGE AND FEED GONSUMPTION IN GILTS FED ICI 33828 AND IODINATED GASEIN FOR 10 DAYS

\begin{tabular}{|c|c|c|c|c|c|c|}
\hline \multicolumn{2}{|c|}{ Mg/gilt/day } & \multirow{3}{*}{$\begin{array}{l}\text { No. } \\
\text { gilts }\end{array}$} & \multirow{2}{*}{\multicolumn{3}{|c|}{$A v \cdot w^{t}(k g)$}} & \multirow{3}{*}{$\begin{array}{c}\text { Total feed } \\
\text { consumed }(\mathrm{kg})\end{array}$} \\
\hline \multirow{2}{*}{$\begin{array}{c}I C I \\
33828\end{array}$} & \multirow{2}{*}{$\begin{array}{l}\text { Iodinated } \\
\text { casein }\end{array}$} & & & & & \\
\hline & & & On feed & Off feed & Change & \\
\hline 0 & 0 & 7 & $152 \cdot 6$ & $152 \cdot 0$ & $-0 \cdot 6$ & 15.5 \\
\hline 0 & 1000 & 7 & $147 \cdot 8$ & $141 \cdot 1$ & $-6 \cdot 7$ & 15.9 \\
\hline 0 & 2000 & 7 & 159.2 & $154 \cdot 4$ & $-5 \cdot 2$ & $15 \cdot 3$ \\
\hline 50 & & 7 & $142 \cdot 8$ & 144.5 & +1.7 & $14 \cdot 8$ \\
\hline 50 & 1000 & 7 & $154 \cdot 1$ & $150 \cdot 3$ & $-3 \cdot 8$ & $13 \cdot 0$ \\
\hline 50 & 2000 & 7 & 156.7 & 151.4 & $-5 \cdot 3$ & $13 \cdot 3$ \\
\hline 150 & 0 & $7^{\mathrm{c}}$ & $156 \cdot 4$ & 157.8 & $+1 \cdot 4$ & $15 \cdot 4$ \\
\hline 150 & 1000 & 7 & $154 \cdot 0$ & $150 \cdot 0$ & -4.0 & $10 \cdot 4$ \\
\hline 150 & 2000 & $7^{\mathrm{c}}$ & $139 \cdot 5$ & 133.0 & $-6 \cdot 5$ & $9 \cdot 3$ \\
\hline 0 & & 21 & $153 \cdot 2$ & $149 \cdot 2$ & $-4 \cdot 1$ & $15 \cdot 6^{b}$ \\
\hline 50 & & 21 & $151 \cdot 2$ & $148 . \overline{7}$ & $-2 \cdot 5$ & $13-7^{\mathrm{a}}, \mathrm{b}$ \\
\hline 150 & & $21^{\mathrm{d}}$ & $150 \cdot 0$ & 147.0 & $-3 \cdot 0$ & $11 \cdot 7^{a}$ \\
\hline & & & $150 \cdot 6$ & $151 \cdot 4$ & & \\
\hline & 1000 & 21 & $151 \cdot 9$ & 147.1 & $-4 \cdot 8^{a}$ & $13 \cdot 1$ \\
\hline & 2000 & $21^{\mathrm{c}}$ & $151 \cdot 8$ & $146 \cdot 2$ & $-5 \cdot 6^{a}$ & $12 \cdot 6$ \\
\hline
\end{tabular}

a, b Mean values with the same superscript within columns within treatment means do not differ $(P<0.01)$.

$c$, One and two missing values for feed consumption data, respectively. Appropriate reduction in d.f. for error term.

iodinated casein, but the tendency for feed intake to decrease as the feeding level of the compound increased is in agreement with the results of Johnson et al. (1959), Dudley et al. (1956) and Wahlstrom (1959). Hypothyroidism is known to reduce appetite and absorption from the gut in the rat (Leathem, 1953) which is paradoxical to the effects reported in the literature for thyroproteins.

Stratman \& First (1969) reported a reduction in the gain in body weight when gilts were fed $116 \mathrm{mg}$ or $232 \mathrm{mg}$ ICI 33828 in $1.82 \mathrm{~kg}$ basal ration for 16 days. Although the gilts fed ICI 33828 in this experiment lost weight, the loss was not significant. The length of the feeding period ( 10 days) may not have been long enough for the $150 \mathrm{mg}$ of ICI 33828 to effect a significant reduction in body weight. Others (Gerrits \& Johnson, 1964; Polge, 1964, 1965) have reported no weight reduction in swine fed comparable levels of ICI 33828.

Significantly $(P<0.01)$ less total feed was consumed when gilts were fed $150 \mathrm{mg}$ of ICI $33828(11.7 \mathrm{~kg})$ as compared to their controls $(15.4 \mathrm{~kg})$. Other researchers (Stratman \& First, 1969; Gerrits, personal communication; Dziuk, 
personal communication) have also reported reduced feed consumption at 150 mg daily or at higher levels of ICI 33828.

One can postulate from these results that the major effect of iodinated casein was an elevated basal metabolic rate which was augmented by a slightly

TABLE 2

OESTRUS OCCURRENGE IN GILTS DURING FEEDING AND AFTER WITHDRAWAL OF ICI 33828 AND IODINATED CASEIN

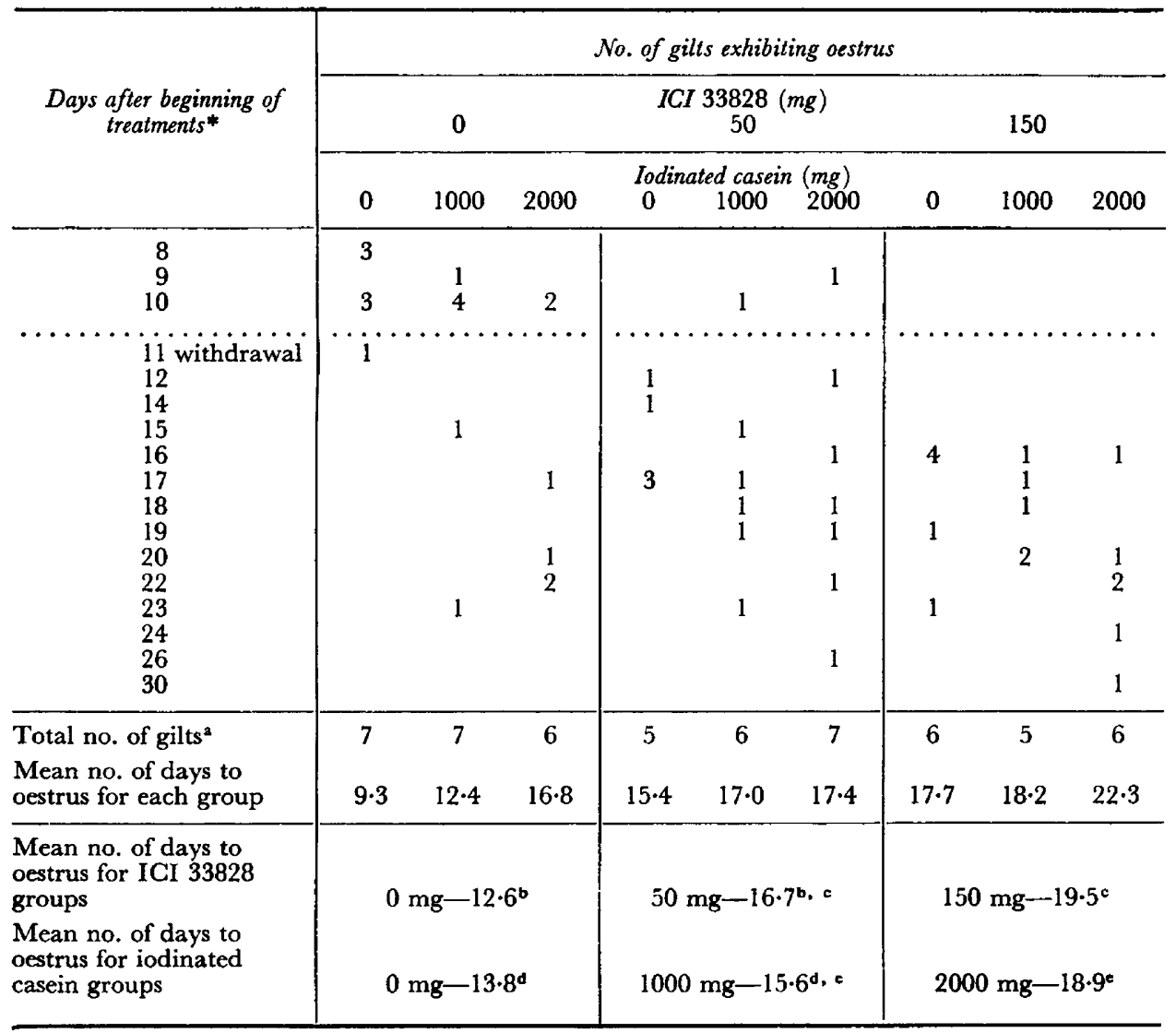

* Day of the first feeding of ICI 33828 and iodinated casein is Day 1.

a Seven gilts per treatment, reduction in number due to those not returning to oestrus by 20 days after withdrawal.

b, c Mean values within treatments with the same superscript do not differ $(P<0.05)$.

d, c Mean values within treatments with the same superscript do not differ $(P<0.01)$.

reduced appetite which resulted in a significant weight loss. The major effect of ICI 33828 appears to be a reduction in appetite mediated through the hypothalamus with a concomitant loss in body weight.

This interval from the beginning of the experimental period on Day 13 of the oestrous cycle to oestrus is shown in Table 2. There were no significant interactions.

All of the control gilts exhibited oestrus during the treatment period or on 
the day of withdrawal. The percentage of gilts exhibiting oestrus during treatment with iodinated casein only decreased as the level increased $(1000 \mathrm{mg}=$ $71.4 \%, 2000 \mathrm{mg}=28.6 \%$ ). None of the gilts exhibited oestrus during treatment with ICI 33828 only. However, two gilts treated with both iodinated casein and ICI 33828 expressed oestrus during treatment.

lodinated casein significantly $(P<0.05)$ increased the interval from the beginning of feeding to oestrus only at the higher level $(2000 \mathrm{mg}=18.9$ days versus controls $=13.8$ days). Ovaries from gilts slaughtered 20 days after withdrawal had small follicles (2 to $3 \mathrm{~mm}$ diameter).

The interval from the beginning of feeding to oestrus was significantly $(P<0.01)$ increased only at the higher levels of ICI 33828 (I50 $\mathrm{mg}=19.5$ days versus their controls $=12 \cdot 6$ days). Gerrits \& Johnson (1964) and Stratman \& First (1969) reported that feeding level of ICI 33828 and interval from withdrawal to oestrus were positively correlated. By contrast, Polge (1965) reported that feeding level had no apparent effect on the interval to oestrus.

A recent report on the influence of oestrogen on the pituitary-thyroid system of the female rat (D'Angelo \& Fisher, 1969) indicated that oestrogen at physiological levels maintains or increases the blood level of TSH, while a high or low level causes a reduction; however, the direct action of oestrogen on thyrotrophin releasing factor (TRF) delivery was tentatively rejected. Boccabella \& Alger (1967) indicate that a transient rise in blood TSH occurs at oestrus in the rat. It has also been demonstrated that ${ }^{131}$ I uptake by the thyroid increases during normal or induced oestrus in the rat (Feldman, 1956). Ovariectomy is also known to suppress TsH secretion and thyroid function in the rat (D'Angelo, 1966).

ICI 33828 is known to increase anterior pituitary levels of LH and FSH (Garbers \& First, 1969; Stormshak, Leverage, Kelley \& Gerrits, 1968; Stratman \& First, unpublished data) in swine. Under the influence of ICI 33828, oestrogen secretion by the ovary would be reduced below physiological levels, thus reducing the level of blood TSH. The decreased TsH would reduce the uptake of ${ }^{131} \mathrm{I}$ by the thyroid and the discharge of thyroid hormone labelled with ${ }^{131} \mathrm{I}$, as Tulloch et al. (1963) have noted in rats treated with ICI 33828.

If these relationships are valid, the postulated hypothyroidism in swine, induced by IGI 33828, would not be overcome by the use of a known hyperthyroid compound.

Under the conditions of this experiment, the inclusion of a hyperthyroid compound (iodinated casein) at different levels did fail to counteract the apparent hypothyroid effect of ICI 33828 on the oestrous cycle. Iodinated casein, however, did reduce weight gains and tended to suppress appetite, thus effecting at least a partial expression of a hyperthyroid condition.

The reason for oestrus inhibition by iodinated casein is unknown. However, under increased levels of thyroxine, an inhibition of TSH directly or indirectly through TRF may occur. The increased level of thyroxine could result in an interaction of thyroid hormone-plasma protein binding mechanisms with oestrogen (D'Angelo \& Fisher, 1969). This would alter oestrogen feedback to the pituitary, resulting in an inhibition of pituitary FSH and LH release, thereby inhibiting oestrus and ovulation in swine. 


\section{AGKNOWLEDGMENTS}

This work is published with the approval of the Director of the Wisconsin Agricultural Experiment Station. It was supported in part by funds from Tri-State Breeder's Cooperative, Westby, Wisconsin; the American Meat Institute, Chicago, Illinois; and Murphy Products Company, Burlington, Wisconsin. During the period of the experiments described in this paper, the author was a Fellow of N.I.H.

\section{REFERENCES}

Boccabella, A. \& Alger, E. A. (1967) Quantitative variations in serum thyrotropin levels during the estrus cycle of the rat. Endocrinology, 81, 121.

CHu, J. P. (1944) Influence of the thyroid gland on pituitary gonadotrophic activity in the rabbit. Endocrinology, 34, 90.

D'Angelo, S. A. (1966) A comparative study of TSH and FSH secretion in rat and guinea pig: effects of gonadectomy and goitrogens. Endocrinology, 78, 1230.

D'Angelo, S. A. \& Fisher, J. S. (1969) Influence of estrogen on the pituitary-thyroid system of the female rat: mechanisms and loci of action. Endocrinology, 84, 117.

Dudley, W. A., Becker, D. E., Jensen, A. H. \& Terrill, S. W. (1956) The influence of a thyroactive compound in diets for swine during lactation. 7. Anim. Sci. 16, 1042.

Feldman, J. D. (1956) Effect of estrus and estrogen on thyroid uptake of $I^{131}$ in rats. Endocrinology, 58, 327.

Garbers, D. L. \& First, N. L. (1969) The effects of injected oestradiol $-17 \beta$, progesterone and dietary ICI 33828 on ovarian and pituitary functions in the sow and gilt. F. Reprod. Fert. 20, 451.

Gerrits, R. J. \& Johnson, L. A. (1964) The effect of an orally administered non-steroid on estrus, ovulation and fertility in gilts. Proc. 5th Int. Congr. Anim. Reprod. 2, 455.

Johnson, C. W., Hays, V. W., Speer, V. C. \& Catron, D. V. (1959) Thyroprotein for lactating sows. J. Anim. Sci. 18, 1224.

Leathem, J. H. (1953) Relationships between thyroid and protein metabolism. In: Protein, Metabolism, Hormones and Growth, p. 17. Rutgers University Press, New Brunswick.

Leathem, J. H. (1958) Hormonal influences on the gonadotrophin sensitive hypothyroid rat ovary. Anat. Rec. 131, 487.

MAQSOOD, M. (1952) Thyroid function in relation to reproduction of mammals and birds. Biol. Rev. $27,281$.

Peterson, R. R., Webster, R. C., Rayner, G. \& Young, W. G. (1952) The thyroid and reproductive performance in the adult female guinea pig. Endocrinology, 51, 504.

Polge, G. (1964) Synchronization of oestrus in pigs by oral administration of ICI compound 33828. Proc. 5th Int. Congr. Anim. Reprod. 2, 388.

Polge, C. (1965) Effective synchronization of estrus in pigs after treatment with ICI compound 33828. Vet. Rec. 77, 232.

Reineke, E. P. \& Soliman, F. A. (1953) Role of thyroid hormone in reproductive physiology of the female. Iowa St. Coll. J. Sci. 28, 67.

Stormshak, F., Leverage, W. E., Jr, Kelley, H. E. \& Gerrits, R. J. (1968) Pituitary and ovarian characteristics of gilts fed Aimax. F. Anim. Sci. 27, 1789 (Abstr.).

Stratman, F. W. \& First, N. L. (1969) Diet consumption, body weight change, and reproductive performance in gilts fed a dithiocarbamoylhydrazine (ICI 33828). 7. Anim. Sci. 28, 353.

Tulloch, N. I., Grooks, J. \& Brown, P. S. (1963) Inhibition of thyroid function by a dithiocarbamoylhydrazine. Nature, Lond. 199, 288.

Warlstrom, R. C. (1959) The effect of feeding thyroactive compounds to lactating sows. Proc. S. Dak. Acad. Sci. 38, 122.

WARner, E. D. \& Meyer, R. K. (1949) The effect of thyroxine on the female reproductive system in parabiotic rats. Endocrinology, 45, 33 . 